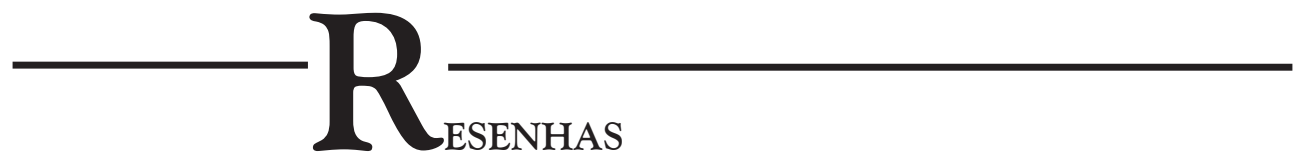

GIUMBELLI, Emerson. Símbolos Religiosos em Controvérsias. São Paulo: TERCEIRO NOME, 2014.

\title{
Resenha: Giumbelli, Emerson. Símbolos Religiosos em Controvérsias. São Paulo: Terceiro Nome, 2014.
}

\author{
Jacqueline Moraes Teixeira \\ Universidade de São Paulo - São Paulo \\ São Paulo - Brasil
}

O livro Símbolos religiosos em controvérsias apresenta desde o título um conjunto de proposições que acompanham a trajetória de pesquisa de seu autor. Emerson Giumbelli - antropólogo que atualmente é professor de antropologia na Universidade Federal do Rio Grande do Sul (UFRGS) e um dos pesquisadores principais do Núcleo de Estudos de Religião (NER) pela mesma instituição -, tem dedicado suas pesquisas as temáticas relacionadas a religiões e modernidade, pensando o modo como a noção de religioso articulou no Brasil um conjunto de símbolos e ideias que organizam nossa concepção pública de nação. 
A obra de Giumbelli nos instiga pensar que a produção de tecnologias para a regulação do religioso produz consequentemente, as configurações do nosso secularismo. Em seu primeiro livro, intitulado $\mathrm{O}$ cuidado dos mortos: Uma história da condenação e legitimação do Espiritismo (1995), o autor analisa a relação entre produção de mecanismos jurídicos para a regulação do religioso e o estabelecimento do Estado Nação no Brasil a partir do conjunto de proibições de reuniões públicas para o exercício do Espiritismo, o que fez com que seu reconhecimento como crença religiosa caminhasse atrelado ao exercício da caridade. A relação entre modernidade e modos de regulação do religioso também é tema de outro livro seu, cujo título é O fim da religião: dilemas da liberdade religiosa no Brasil e na França (2002). Nele, Giumbelli tece uma cuidadosa e obstinada investigação acerca da concepção francesa de religião civil e da construção moderna da liberdade religiosa, apresentando seu percurso histórico na França e no Brasil, onde dedica os capítulos finais a participação da Igreja Universal do Reino de Deus na arena política brasileira.

Símbolos religiosos em controvérsias reúne um conjunto de artigos fruto de pesquisas produzidas por Giumbelli nesta última década e também se insere nessa agenda heurística de pensar as relações entre modernidade e religião, apresentando como recorte empírico e caminho analítico eventos relevantes contribuindo diretamente para a compreensão dos desafios contemporâneos no campo de estudos sobre religiões no Brasil.

O uso do conceito de controvérsia, ora como categoria analítica, ora como inspiração metodológica insere este livro numa temática muito contemporânea dos estudos sócio-antropológicos sobre religiões e religiosidade, ao propor pensar os símbolos religiosos a partir de uma intersecção com a política. Para tanto, Giumbelli enfrenta o tema da laicidade pensando o modo como alguns símbolos religiosos são interpretados pela multiplicidade de atores. As múltiplas concepções para laicidade e para religião emergem, portanto, da agência e interação de atores e símbolos.

A economia do texto desdobra-se, sobretudo, por meio de uma análise dos discursos, cuja fonte é documentos históricos, entrevistas, processos jurídicos, noticiários e relatos tecendo uma rede que contempla argumentos individuais e trajetórias institucionais. Os capítulos estruturam-se em duas operações metodológicas importantes, o registro dos múltiplos caminhos de circulação dos discursos,exercício importante na constituição de uma análise de controvérsia, e, uma espécie de genealogia da controvérsia que permite aos leitores o acesso a uma historiografia acerca da presença de determinados símbolos religiosos no espaço público.

O capítulo primeiro, intitulado Paris, Praça Tiradentes: laicidade e símbolos religiosos no Brasil apresenta uma genealogia da constituição do Brasil como Estado nação a partir da emergência de símbolos religiosos que passam a ser reconhecidos como símbolos nacionais. Tal exercício inicia-se pela descrição densa da tela de Pedro Bruno intitulada "A Pátria" (1919). Trata-se de um quadro historicamente celebrado como importante emblema republicano que reúne num mesmo cenário a casa como espaço da articulação da laicidade e do religioso, a bandeira nacional desconstruída na mão 
das crianças, as mulheres que fazem a pátria, o cuidado feminino com os filhos da nação, o sacrifício de Tiradentes, que como demonstra o texto, passa a ser representado em retratos com traços fenotípicos semelhantes aos utilizados nas representações de Cristo. Partindo do exercício historiográfico de José Murilo de Carvalho, Giumbelli traça um paralelo entre os caminhos distintos percorridos no Brasil e na França em relação as representações da nova república como figura feminina, algo que no Brasil se assentou na imagem de Nossa Senhora de Aparecida. Para o autor, a proeminência de alguns símbolos religiosos em espaços públicos se constituiu como tecnologia fundamental para a emergência de um discurso sobre a laicidade da nação.

Dessa articulação entre símbolos religiosos e laicidade da nação surge na década de trinta, na cidade do Rio de Janeiro, o Cristo Redentor. No capítulo dois, Giumbelli apresenta uma interessante etnografia acerca da produção do Cristo Redentor como símbolo da pátria, pensando na maneira como religião e modernidade são operadas de modo a produzir no processo de construção deste monumento religioso, a materialização de concepções modernas tanto no campo das artes, como no campo das instituições políticas nacionais. O Cristo Redentor como emblema foi idealizado para representar a força política do catolicismo no Brasil, porém, seu potencial agenciador de significados não parou por aí. A pluralidade de sentidos atribuídos ao monumento transita de imagem religiosa a representante cultural, e mesmo, como ícone do turismo nacional, permitindo com que pessoas de diferentes confissões religiosas convivam e celebrem sua figura pública. Giumbelli destaca que a polivalência de sentidos sobre o monumento do Cristo Redentor também podem ser atribuídos à modernidade, situando no texto o conceito de "modernidades alternativas" de Otávio Velho, sugerindo que, antes de ser uma localidade, modernidade diz respeito a posições discursivas.

A análise de Giumbelli acerca do Cristo Redentor continua no capítulo três, cujo objetivo central do texto aparece desde seu título, a saber, Brasileiro e europeu: a construção da nacionalidade em torno do monumento ao Cristo Redentor do Corcovado. $\mathrm{O}$ texto apresenta um conjunto de eventos promovidos pela Igreja católica nas décadas de vinte e trinta do século XX para se consolidar a associação entre cristianismo de tradição católica e nacionalidade. A dimensão nacionalizadora desses discursos também se deu no âmbito político onde a Igreja Católica se inseria como representante autorizada da monarquia divina, responsável por assegurar que essa nova nação jamais se esqueceria de seu passado cristão. Os movimentos para a nacionalização do Cristo carioca também se apoiavam em políticas para a internacionalização de uma imagem sobre o Brasil, sobretudo, como modelo de catolicidade. Novamente apostando na fluidez de sentidos na construção de um símbolo como o Cristo Redentor, Giumbelli aponta para a dimensão prática e ao mesmo tempo paradoxal que envolve as concepções como "nacional" e "estrangeiro".

O Capítulo quatro foi escrito por Giumbelli em co-autoria com Izabella Bosisio, que também é antropóloga, doutoranda na Universidade Federal do Rio Grande do Sul (UFRGS). Intitulado A política de um monumento: as muitas imagens do Cristo 
Redentor, autor e autora realizam uma etnografia documental e uma análise dos múltiplos registros do monumento do Cristo Redentor nos livros sobre os monumentos da Cidade do Rio de Janeiro, publicados entre as décadas de quarenta e oitenta. $\mathrm{O}$ percurso documental tracejado no texto revela as inúmeras camadas de sentidos sociais que constituíram a grandeza e a materialidade do Cristo Redentor, perpassando discursos artísticos, religiosos, urbano e político, tornando-o emblema da nação. A dissociação do monumento do Cristo Redentor como símbolo religioso, algo que permeou os movimentos para promovê-lo entre as sete maravilhas do mundo, permite o uso da noção iconoclash, cunhada por Bruno Latour, para pensar processos de polissemia e polivalência sofridos por imagens religiosas.

Ainda no exercício de pensar os processos de polissemia e de polivalência que constroem a materialidade de sentidos da imagem do Cristo Redentor, Giumbelli dedica o capítulo cinco a análise dos usos de um monumento nacional como equipamento urbano. O Cristo pichado: sacralidade e transgressão de um monumento urbano se inicia com a narrativa de um evento que resultou em grande polêmica no ano de 2010 quando a estátua do Cristo redentor teve seu rosto, braços e peito pichados. Uma ação de potencial midiático foi montada para tentar descobrir e punir os autores da pichação. O primeiro desafio analítico que Giumbelli propõe é tentar se distanciar de interpretar tal acontecimento como uma afronta a ordem das coisas, se distanciando da noção de drama social. Para ele, "a pichação pode ser entendida como um jogo de encadeamentos, os quais caracterizam a própria existência do monumento alvejado e a sua relação com a cidade que o abriga" (p. 111). A polêmica gerada em torno da pichação do Cristo e novas disputas acerca dos sentidos atribuídos ao monumento permite ao autor pensar a dimensão prática e experiencial de uma controvérsia, que coloca os sentidos em disputa, redefinindo a natureza do monumento.

No capítulo seis o foco da análise recai sobre outro símbolo considerado comum ao catolicismo, os crucifixos. Intitulado Crucifixos invisiveis: polêmicas recentes no Brasil sobre símbolos religiosos em recintos estatais, Giumbelli encara a polêmica acerca da presença de crucifixos em determinados espaços públicos tidos como símbolos da laicidade das instituições modernas. Para o autor, laicidade é abordada em sua análise da mesma maneira que religião e modernidade, como categoria plural cujos sentidos são definidos nas relações sociais agenciadas na dinâmica de uma controvérsia. Nesse caso, a noção de laicidade esta sendo disputada entre atores favoráveis e contrários a manutenção de crucifixos em instituições públicas. . A descrição das posições discursivas que constituem a controvérsia apresentada nesse capítulo permite ao autor demonstrar a polissemia de sentidos para a laicidade, algo que é performatizado nas múltiplas possibilidades de agência da imagem do crucifixo. Assim, dispor o crucifixo como cerne da controvérsia acerca da laicidade dos espaços do poder estatal produz um efeito revelador colocando o crucifixo na esfera da visibilidade.

O capítulo seguinte apresenta os sentidos distintos, historicamente atribuídos ao monumento do Cristo Redentor e aos crucifixos dos espaços institucionais do Esta- 
do. Intitulado, Crucifixo em recintos estatais e o monumento do Cristo Redentor, o texto traça um paralelo na agência social destes símbolos, enquanto o monumento do Cristo Redentor pode ser pensado como a performance da visibilidade e os crucifixos pode ser pensado como a exata medida da invisibilidade. Tais abordagens sociais distintas acabam por alargar os sentidos seculares dos crucifixos, que, na retórica de seus defensores passa a se traduzir como objeto cultural, fundamental ao imaginário nacional e, consequentemente, reaproximar estátua do Cristo Redentor de seu sentido religioso o que acaba por produzir uma controvérsia pública acerca da dimensão religiosa e secular desses símbolos. Para Giumbelli os conflitos e disputas que emergem na cena pública no debate acerca o uso de ambos os símbolos permite pensar não apenas numa relação entre símbolos religiosos e espaço público, mas na produção da própria concepção de público que é agenciada pela apropriação, circulação e visibilidade dos objetos em questão.

Se o caráter público dos espaços se dá nas relações, o capítulo oitavo introduz uma indagação bastante perspicaz: o que consiste um ambiente laico? A resposta se constrói a partir da etnografia situada na cidade de Porto Alegre (RS) em "capelas ecumênicas" comum em espaços de uso coletivo, tais como hospitais, universidades, fóruns, etc. Assim, em O que é um ambiente laico? Espaços (inter) religiosos em instituições públicas, Giumbelli apresenta como cenário para a controvérsia acerca da laicidade dos espaços públicos um debate que circundou os usos e pertencimentos da capela católica do Hospital das Clínicas de Porto Alegre. A interpelação que nomeia o capítulo também organiza uma teia complexa de sentidos, de um lado a Igreja Católica que constituiu o espaço, definiu objetos e, portanto, pensava manter o espaço para uso majoritário de ritos católicos, de outro, o projeto do Espaço Espiritualidade, que defendia que o local deveria ser de uso ecumênico, sem imagens religiosas, visando incluir a diversidade de pessoas que circulam num hospital público.

Na controvérsia em questão, a defesa da laicidade se deu no exercício prático de se pensar a legitimidade e a dimensão religiosa de um espaço reconhecidamente público. Nesse caso, a defesa do público justificou-se pela multiplicidade de pertencimentos religiosos por parte dos usuários do Hospital. Giumbelli salienta que para além do uso político comum às disputas jurídicas, a categoria laicidade conquistou nas ciências sociais o estatuto de conceito o que acaba por suscitar um exercício teórico no qual se torna impossível pensá-la sem considerar seus princípios filosóficos, ou mesmo seu uso político.

O capítulo nove é dedicado aos movimentos evangélicos. Intitulado Cultura pública: evangélicos e sua presença na sociedade brasileira, o autor se debruça sobre a presença constante de evangélicos no cenário político nacional. Para pensar uma noção específica de cultura pública, é importante entender em quais sentidos a presença evangélica na esfera pública é distinta em relação a outros seguimentos religiosos importantes para a construção da nossa identidade nacional. O catolicismo possui centralidade por ter sido incorporado como "religião civil" sendo majoritário na representação de muitos dos nossos símbolos nacionais (como bem demonstra o livro), 
além disso, a religiosidade católica se constituiu como gramática universal absorvendo a história do país o que permitiu alguma aproximação com ritos e entidades das religiões afro-brasileiras. Para Giumbelli, enquanto o catolicismo e as religiões afro-brasileiras operam com as categorias tradição e cultura imaterial, a temporalidade que marca a ação pública dos movimentos evangélicos é uma concepção específica de futuro. Essa temporalidade marca as inúmeras estratégias de visibilidade da "cultura pública" evangélica que passa a se ocupar da mídia, investindo em programas e performances de exorcismo na televisão, na ocupação das ruas em marchas e ajuntamentos realizados nas grandes cidades, na presença constante nos transportes públicos, nas favelas e nas prisões. De modo que, se num primeiro momento da história do Brasil, o catolicismo ofereceu uma materialidade de símbolos para constituir espaços de centralidade, e consequentemente, se construir a nação, a "cultura pública" evangélica se alarga em meio a multiplicidade de equipamentos urbanos e de comunicação conformando novos modos de ocupação e novos espaços de experiência, se projetando como equipamento importante de interação e visibilidade.

Os símbolos religiosos suscitam debates cujo objetivo é a disputa pela constituição da dimensão pública de alguns espaços, algo que acaba por produzir dispositivos para a regulação do religioso. Giumbelli introduz esse debate no último capítulo do livro, cujo título é O problema do secularismo e da regulação do religioso: uma perspectiva antropológica, a partir de um exercício comparativo entre Brasil, Estados Unidos e França. Cabe destacar que o capítulo se desenvolve de modo a apresentar uma genealogia do conceito de secularismo pensado na disciplina antropológica e recuperado aqui um pouco em forma de controvérsia, o que permite acompanhar o debate e a produção teórica acerca desta temática nos Estados Unidos e na França.

Esse capítulo nos remete a uma importante abordagem, algo que também considero central na antropologia de Giumbelli, que diz respeito não ao secularismo como objeto empírico, mas sim, ao modo como secularismo torna-se um problema, e nesse caso específico, como suas configurações são pensadas articuladas ao uso dos símbolos religiosos. Para tanto, Giumbelli se aproxima de uma chave foucaultiana e propõe pensar o religioso como modos de regulação, processo no qual "há situações em que a regulação do religioso opera-se indiretamente, pelas conseqüências derivadas das normatizações das outras esferas sociais" (p.221).

A disposição apresentada por Giumbelli (nesse livro em particular e na sua produção antropológica de modo mais geral) de pensar a regulação do religioso como um dispositivo produtor de inúmeras materialidades, algo que perpassa inclusive, as configurações do que entendemos como modernidade, me parece fundamental como instrumento analítico, principalmente, em tempos da atual crise nacional, na qual disputar os símbolos e discutir os limites do religioso e a importância da laicidade tornou-se a principal gramática das interações no espaço público.

Assim, acredito que o livro de Emerson Giumbelli contribui muitíssimo para o aprofundamento das discussões sobre o tema da laicidade e das relações entre 
Estado, religião e os sentidos do espaço público no Brasil, oferecendo-nos uma perspectiva que nos permite pensar as tensões atuais para além da clássica polarização entre o religioso e o secular.

\section{Referencias Bibliográficas}

GIUMBELLI, Emerson. Símbolos Religiosos em Controvérsias. São Paulo: TERCEIRO NOME, 2014. Editorial, 2002

. O fim da religião: dilemas da liberdade religiosa no Brasil e na França. São Paulo. Attar

.O cuidado dos mortos: Uma história da condenação e Legitimação do Espiritismo. Rio de Janeiro. Arquivo Nacional , 1997

\section{Jacqueline Moraes Teixeira}

Doutoranda do Programa de Pós Graduação em Antropologia Social (PPGAS/ USP), pesquisadora do Nau/USP (Laboratório de Antropologia Urbana) e do Cebrap (Centro Brasileiro de Análise e Planejamento). 